\title{
Dynamic Testing of UAV Navigation System
}

\author{
V.M. Sineglazov \\ Aviation Computer-Integrated Complexes Department, \\ Educational \& Research Institute of Information and \\ Diagnostic Systems, \\ National Aviation University \\ Kyiv, Ukraine \\ svm@nau.edu.ua
}

\author{
S.O. Dolgorukov \\ Aviation Computer-Integrated Complexes Department, \\ Educational \& Research Institute of Information and \\ Diagnostic Systems, \\ National Aviation University \\ Kyiv, Ukraine \\ sdolgorukov@nau.edu.ua
}

\begin{abstract}
The paper considers dynamic test table system for navigation sensors testing and verification. The problem of test table confidence margin is considered taking into account different sources of errors. Estimation of frequency characteristics of sensors is shown by special test table criteria. The paper describes inertial navigation system experiment on dynamic test table in order to compensate navigation system parameters.
\end{abstract}

Keywords—navigation system; three-axis test table; unmanned aerial vehicle; dynamic test table system

\section{INTRODUCTION}

Last decades have seen an increasing amount of aircrafts that do not have a manned pilot on board. Unmanned aerial vehicle (UAV) is the component of unmanned aircraft systems (UAS) or remotely piloted aircraft systems (RPAS).

The extensive use of UAVs demands highly trained human operator in RPAS or advanced autonomous control in UAS to be present. This causes UAVs to be expensive, and causes a challenge for engineers to design a reliable autonomous controller and to develop appropriate means to safely validate the designed controllers without crashing the involved UAVs. Spatial information plays a critical role in ensuring that the designed flight controller works properly minimizing the possibility of crashing the real UAV. The motion data are obtained using the appropriate sensors and sensory units like Inertial Navigation Systems (INS) and Inertial Measurement Units (IMUs).

Inertial Measurement Unit was at most expensive until the recent development of cheap ceramic and silicon sensors, which has lowered their price and the quality of their measurements. Today IMUs are available at a low cost. The major problems encountered with cheap IMUs are the need to perform the calibration process for the used sensors, and the need to filter the existing noise at the output signals due vibrations and measurements noise.

\section{Dynamic Test Table Design Review}

Dynamic Test Table System (DTTS) provide angular position, rate and acceleration motions for development and production testing of inertial components, subsystems and modules as well as real time modeling of the whole UAV systems. Three-axis test table (TT) which is part of the DTTS must ensure tests on the spatial parameters close to real at the same time conforming the requirements of the device under the test (Fig. 1).

These TTs, both newly created and modernized, have the following characteristic features.
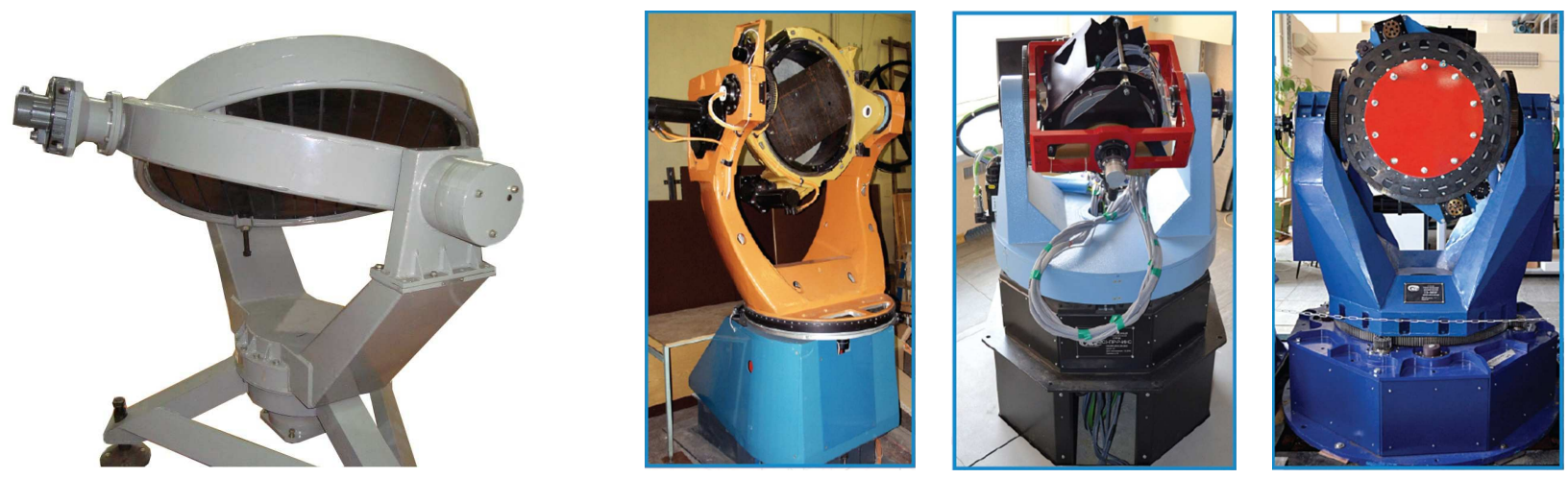

Fig. 1. Three axis test table for INS dynamic testing.

The rotary support mechanisms (RSM) of the TTs, are designed according to traditional and original kinematic and constructive schemes taking into account the provision of maximum rigidity with the minimum possible moments of inertia. Minimization of backlash and frictional moments are required in the manufacturing of RSM for TTs ensuring the 
required kinematic accuracy. High-precision assemblies are used in RSM designs: large-diameter bearings, precision guides with carriages on roller bearings and linear bearings, high-strength hollow profiles for frame structures, power and instrument gearboxes. DTTS have a digital control system with a built-in industrial computer and specialized software.

The control system uses drives based on brushless synchronous motors with permanent magnets on the rotor and intelligent servo controllers, serial digital absolute encoder sensors for measuring the TT corresponding channel position.

In the control cabinet are located servo controllers of drives, specialized control units, built-in computer with a monitor, start-up equipment. The built-in computer, which is the intellectual core of the control system, is equipped with a set of interface modules and input/output modules. Specialized software provides the following functions:

- formation of a position profile with correcting links;

- support for exchange procedures between and user interface;

- autonomous testing and setting of servo drives;

- test table management, providing safe operation in emergency situations;

- the organization of an information board on the monitor screen of the built-in computer with the current status of the drives, alarm messages.

Specialized control system units perform the following functions:

- analysis, transformation and transmission of control signals to servo controllers; collection, analysis, transformation and transmission of status information to ensure safe operation in working and test modes and in emergency situations;

- preparation and power-up; control of brake clutches of electric motors; implementation of the dynamic braking mode.

To calculate the error margin $\delta$ [1], a confidence probability of $P=0.95$ is assumed. Due to the equal order of influence of errors, the calculated value of the limit of the relative error of the test table is defined as

$$
\delta=1.1 \sqrt{\delta_{\mathrm{m}}^{2}+\delta_{\mathrm{el}}^{2}+\delta_{\mathrm{ca}}^{2}+\delta_{\mathrm{sens}}^{2}+\delta_{\mathrm{d}}^{2}+\delta_{\mathrm{s}}^{2}},
$$

where $\delta_{\mathrm{m}}$ and $\delta_{\mathrm{el}}$ is the limit of errors due to the mechanical and electronic systems; $\delta_{\mathrm{ca}}$ is the error limit due to control algorithms; $\delta_{\text {sens }}$ is the limit of the error of the sensors; $\delta_{\mathrm{d}}$ is the error limit of the digital to analog converters (DACs); $\delta_{\mathrm{s}}$ is the error limit due to the sampling frequency of the control signal.

Below is the chart reflecting the distribution of errors in the test table (Fig. 2).

According to the chart, after introducing the required value of the angular velocity $\varphi_{0}$, the control system generates a control action applied to the drive, after which the platform starts to move with some actual angular velocity $\varphi_{\mathrm{a}}$. The measured value of the angular velocity $\varphi_{m}$ is different from the actual one due to the errors of the $\xi_{\mathrm{a}}$ angle sensor and the $\xi_{\mathrm{s}}$ sampling. The control action is formed with the error of the control algorithms $\xi_{\mathrm{c}}$ and the DAC bit width $\xi_{\mathrm{d}}$. Due to the control scheme for angle and angular velocity of the platform, the errors of mechanical $\xi_{\mathrm{m}}$ and electronic systems $\xi_{\mathrm{el}}$ are largely compensated by the control system.

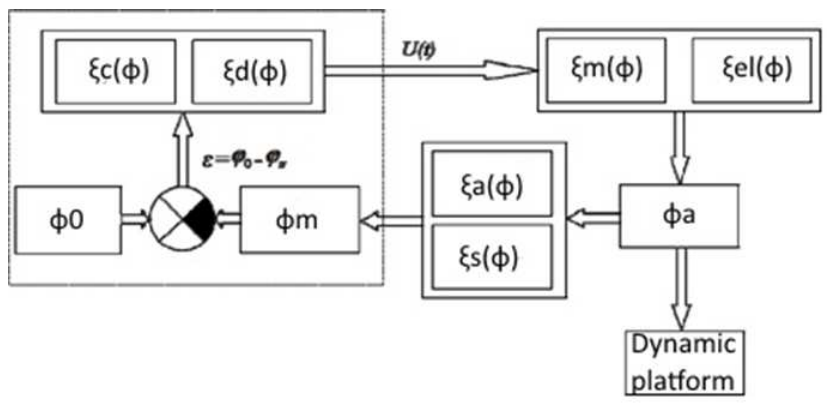

Fig. 2. Distribution of errors in the test table.

The main characteristics of the testing equipment for providing the constant angular velocities are given in the general summary Table I

TABLE I. MAIN CHARACTERISTICS OF TESTING EQUIPMENT

\begin{tabular}{|c|c|}
\hline \multicolumn{2}{|c|}{ International manufacturers } \\
\hline $\boldsymbol{1}$ & $\mathbf{2}$ \\
\hline Angular speed ranges available & from \pm 500 to $\pm 10000 \mathrm{deg} / \mathrm{s}$ \\
\hline $\begin{array}{c}\text { Minimum reproducible angular } \\
\text { velocity }\end{array}$ & $0,0001-0,00001^{\circ} \mathrm{s}$ \\
\hline $\begin{array}{c}\text { Angular speed input } \\
\text { signal error }\end{array}$ & Typical values: \\
& $0.0001 \%$ by $360^{\circ} ;$ \\
& $0,01-0.001 \%$ by $10^{\circ} ;$ \\
& $0,1-0.01 \%$ by $1^{\circ} ;$ \\
\hline & The error is not divided into a \\
Post USSR manufacturers \\
\hline Angular positioning error & range of reproducible angular \\
\hline Angular speed ranges available & from \pm 150 to $\pm 10000 \mathrm{deg} / \mathrm{s}$ \\
\hline Minimum reproducible angular & from 0.0005 to $0,01 \mathrm{deg} / \mathrm{s}$ \\
\hline velocity & Typical values: \\
\hline Angular speed input & from 0,01 to $0,00001 \% \mathrm{by} 360^{\circ}$ \\
signal error & About $0,001 \%$ by $1^{\circ}$ \\
\hline Angular positioning error & from $1-2$ to 20 angular sec. \\
\hline
\end{tabular}

\section{ESTIMATION OF FREQUENCY CHARACTERISTICS OF} SENSORS

In order to estimate the dynamic characteristics of IMU, their frequency characteristics are usually used. To solve this problem, as a rule, TTs of various designs are used. Such test equipment can be classified according to several criteria.

In terms of the number of axes, the stands are divided into one-, two-, and multi-axes. Most of the stands [2], [3], [5], in addition to rotation, can reproduce angular oscillations with frequencies from 10 to $50 \mathrm{~Hz}$. Depending on the number of axes, a different movement type of the platform (flat or 
spatial) is reproduced. However, such equipment is not designed for these operating modes due to significant bearing wear and drive operation in the inhibited mode.

It should be noted that in recent years there have appeared on the market TTs with a significant number of rotation axes [2], [5], capable of reproducing the mutual spatial position of two objects (for example, a target aircraft) for testing homing heads.

According to the mass-size characteristics, the TTs can be divided into portable [8] and stationary for testing large measuring complexes [9], [10]. As a rule, stationary TTs reproduce motion with a frequency not exceeding $1 \mathrm{~Hz}$. Portable TTs are designed to reproduce high-frequency oscillations and have a larger operating frequency range.

At present, most of the existing TTs are able to reproduce oscillations in a certain frequency range [11], [12], but there are installations operating in resonant mode at the same frequency [13]. They are capable of suppressing higher harmonics accompanying harmonic oscillations and influencing the accuracy of reproduction of oscillations. However, the use of such devices for the dynamic calibration of sensors has not become widespread due to the complex change in the working resonance frequency by software adjustment and selection of loads and torsion bars.

To provide the required characteristics of the testing equipment, it is possible to use both an open control system for the TTs [10] and a closed feedback loop for controlling the motors [14].

The classification of the test equipment according to the specified criteria is shown in Fig. 3.

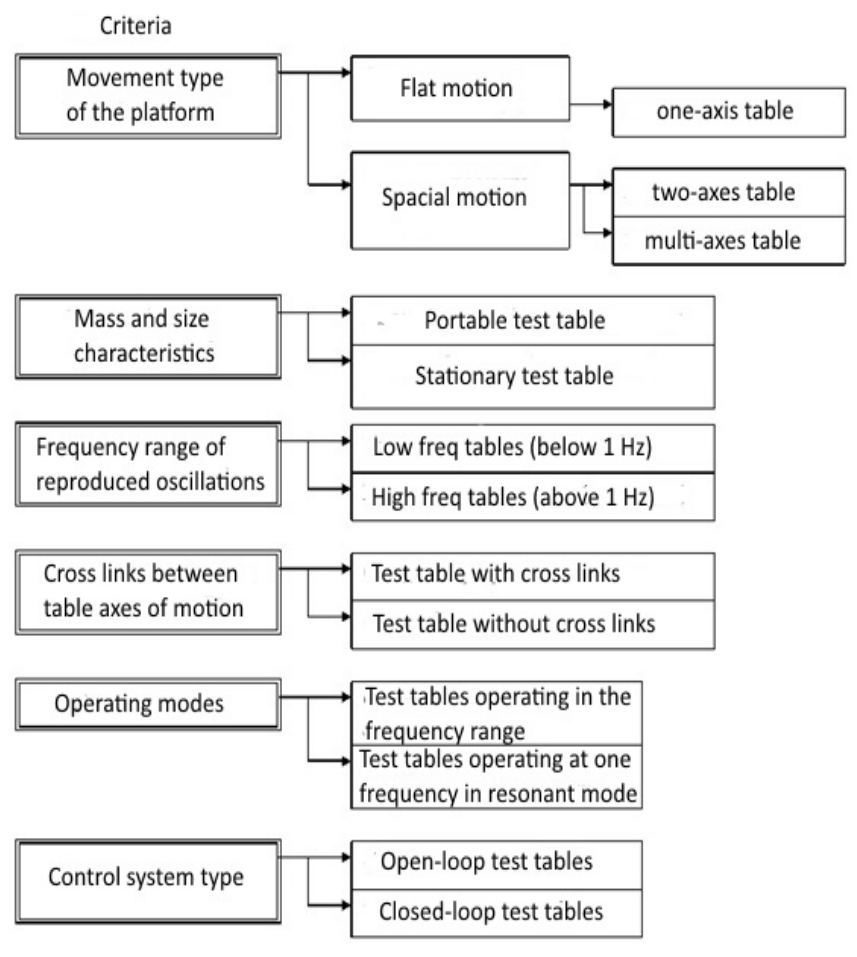

Fig. 3. Classification of testing equipment for assessing the kinematic characteristics of sensors and systems.

\section{EXPERIMENT Plan AND RESUlts}

Experiments were carried out on a three axis precision test table IXBlue EVO $30 \mathrm{~L}$ [7]. According to the above classification it is stationary $3000 \mathrm{~kg}$, high frequency test table, which operated in frequency range up to $100 \mathrm{~Hz}$ and rates up to $3000 \mathrm{deg} / \mathrm{sec}$. Three cycles of 40 minutes duration tests were performed using a INS. In each of tests the corresponding instrument axis of the INS was set to be a horizontal axis of rotation. The angular velocity of rotation was piecewise constant and set by two values of the rate is $2 \mathrm{deg} / \mathrm{s}$ and $5 \mathrm{deg} / \mathrm{s}$ (Fig. 4).

In the experiments, the following output parameters of INS were registered:

- coordinates - latitude and longitude $\varphi, \lambda$;

- north and east speed components $\mathrm{V}_{\mathrm{N}}, \mathrm{V}_{\mathrm{E}}$;

- angles of orientation of the INS $\gamma, \theta, \psi$;

- angular velocities of the INS instrumental trihedron $\omega_{z 1}, \omega_{z 2}, \omega_{z 3}$.

In both experiments, the system after the setting up on the table was changed into navigation mode. In the first experiment, INS has accumulated about $15 \mathrm{~km}$ of error in determining the coordinates, in the second - about $12 \mathrm{~km}$.

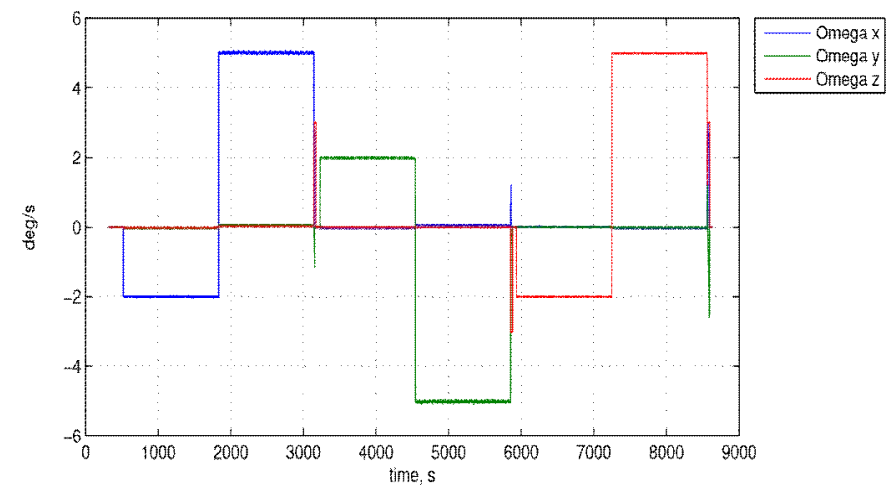

Fig. 4. Angular speed of INS, deg/s.

The experiments were processed using secondary information. The first experiment was used to estimate the parameters of instrumental errors, i.e. for calibration, and the second - to compensate for errors based on estimates obtained in the first experiment.

As a result of processing the data of the first experiment, the following estimates of instrumental errors were obtained as shown in the Table II.

Then the compensation of the errors was performed on the data of the second experiment. Compensation was carried out in the following way: INS error equations were solved numerically on the data of the second experiment. As the values of instrumental errors were used the above estimates obtained in the previous experiment, the remaining initial values were set to zero. The coordinate errors obtained as a result of solving the INS error equations in the corresponding dimensions were subtracted from coordinate values of the INS data. 
TABLE II. ESTIMATES OF INSTRUMENTAL ERRORS

\begin{tabular}{|c|c|c|c|c|c|}
\hline$v_{z_{1}}^{0}, \circ / \mathrm{h}$ & $v_{z_{2}}^{0},{ }^{\circ} / \mathrm{h}$ & $v_{z_{3}}^{0}, \circ / \mathrm{h}$ & $\begin{array}{l}\Delta f_{z_{1}}^{0} \\
\mathrm{~m} / \mathrm{s}^{2}\end{array}$ & $\begin{array}{l}\Delta f_{z_{2}}^{0} \\
\mathrm{~m} / \mathrm{s}^{2}\end{array}$ & $\begin{array}{l}\Delta f_{z_{3}}^{0} \\
\mathrm{~m} / \mathrm{s}^{2}\end{array}$ \\
\hline 0.015 & 0.007 & 0.023 & $-7.8 \cdot 10^{-4}$ & $-5.8 \cdot 10^{-5}$ & $-2.4 \cdot 10^{-3}$ \\
\hline$\Gamma 11$ & $\Gamma 21$ & $\Gamma 22$ & $\Gamma 31$ & Г32 & $\Gamma 33$ \\
\hline $1 \cdot 10^{-4}$ & $1.3 \cdot 10^{-4}$ & $-2.8 \cdot 10^{-5}$ & $-9.6 \cdot 10^{-5}$ & $5.6 \cdot 10^{-5}$ & $-7 \cdot 10^{-5}$ \\
\hline$\theta 11$ & $\theta 12$ & $\theta 13$ & $\theta 21$ & $\theta 22$ & $\theta 23$ \\
\hline \multirow[t]{3}{*}{$7.6 \cdot 10^{-6}$} & $-1.3 \cdot 10^{-4}$ & $6.7 \cdot 10^{-5}$ & $-5.3 \cdot 10^{-5}$ & $9.4 \cdot 10^{-6}$ & $2.1 \cdot 10^{-5}$ \\
\hline & $\theta 31$ & $\theta 32$ & $\theta 33$ & & \\
\hline & $-2.3 \cdot 10^{-5}$ & $-7.8 \cdot 10^{-5}$ & $1.6 \cdot 10^{-6}$ & & \\
\hline
\end{tabular}

The initial coordinates of INS and corrected ones were compared with the reference parameters - the coordinates of the test table.

The Fig. 5 shows that the initial errors have decreased by at least 3 times.

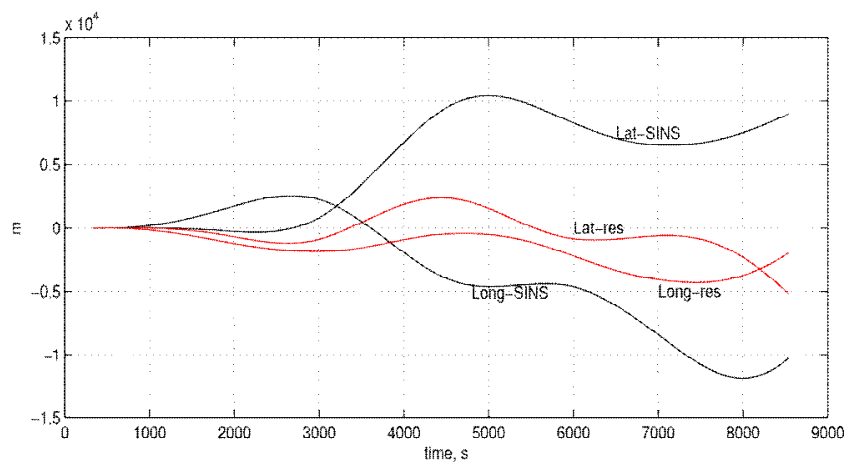

Fig. 5. INS errors in determining coordinates before and after compensation.

\section{CONCLUSION}

Dynamic test table system can be effectively used for UAV navigation systems test, such as inertial navigation system. Depending on the characteristics of the sensors under the test it is necessary to choose corresponding test table. Moreover, to insure credibility of the results in the process of development or operation of DTTS correct error margin estimation is essential. Three-axes dynamic test table developed in the National Aviation University can bring UAV testing to the new quality level and decrease development, production and operation cost of unmanned aircraft systems or remotely piloted aircrafts.

\section{REFERENCES}

[1] A.B. Chekmarev, Razrabotka i issledovanie stenda dlja dinamicheskoj kalibrovki mikromehanicheskih inercialnyh datchikov. $\mathrm{PhD}$ thesis, Saint Petersburg, 2013.

[2] URL: http://acutronic.com/ru/

[3] URL: http://www.actidyn.com/

[4] URL: http://www.ideal-aerosmith.com/

[5] URL: http://www.wuilfert.com

[6] D.G. Gryazin, O.O. Velitchko, and A.B. Chekmarev, Measurement assurance of micromechanical sensors and units testing. Izvestija Tulskogo gosudarstvennogo universiteta. Tehnicheskie nauki. vol. 7, pp. 67-77, 2012

[7] I. A. Vasinjova, Kalibrovka beskardannoj inercialnoj navigacionnoj sistemy v sbore na tochnyh stendah. PhD thesis, Lomonosov Moscow State University, 2017.

[8] Patent of Russian Federation № 2007132944/28 Dvuhstepennoj stend dlja zadanija uglovyh kolebanij: pat. 2367921S2.

[9] Yu.V. Filatov, et al. "Stand for testing inertial navigation systems" Collected theses of the Third All-Russian Scientific and Technical Conference Measurements and tests in shipbuilding and related industries (Sudometrica 2008), p. 54, October 18-20, 2010, St. Petersburg. SPb., 2010.

[10] Stand for the control of gyroscopic instruments: scientific. tr. NGO Azimut. L., 1990.

[11] V.A Ivanov., N.S.Solovyeva, and B.L. Suslov, "Two-Axis Plant for Calibration and Grading of Angular Accelerometers." Proceedings of Metrological Institutes of the USSR. Measurement of angular accelerations. pp. 5-12, issue 143 (203), 1973.

[12] S.F. Levanov, "Installation for the reproduction of harmonic angular accelerations in the frequency range from 0.05 to $0.6 \mathrm{~Hz}$." Proceedings of the metrological institutes of the USSR. Studies in the field of measurements of angular parameters of motion. pp. 89-92, issue 206 (266), 1977.

[13] V.A. Ivanov and V.M. Menchikov, "Resonance model installation." Devices and control systems. pp. 39-41, vol. 7, 1976.

[14] Three-axes dynamic test table: scientific works. KIIGA. Kiev, 1991.

[15] A.B. Chekmarev, "Stand for monitoring the frequency characteristics of micromechanical gyroscopes and modules based on them." Navigation and traffic management: Reports of the XII conference of young scientists "Navigation and traffic management." SPb: SSC RF Concern "CSRI Elektropribor", p. 408, 2010. 